\title{
Aspects of Two Corrosion Processes Relevant to Military Hardware
}

J. W. Braithwaite, R. G. Buchheit

Prepared by

Sandia National Laboratories

Albuquerque, New Mexico 87185 and Livermore, California 94550.

Sandia is a multiprogram laboratory operated by Sandia Corporation, a Lockheed Martin Company, for the United States Department of Energy under Contract DE-AC04-94AL85000.

Approved for public release; further dissemination unlimited.

\section{Sandia National Laboratories}
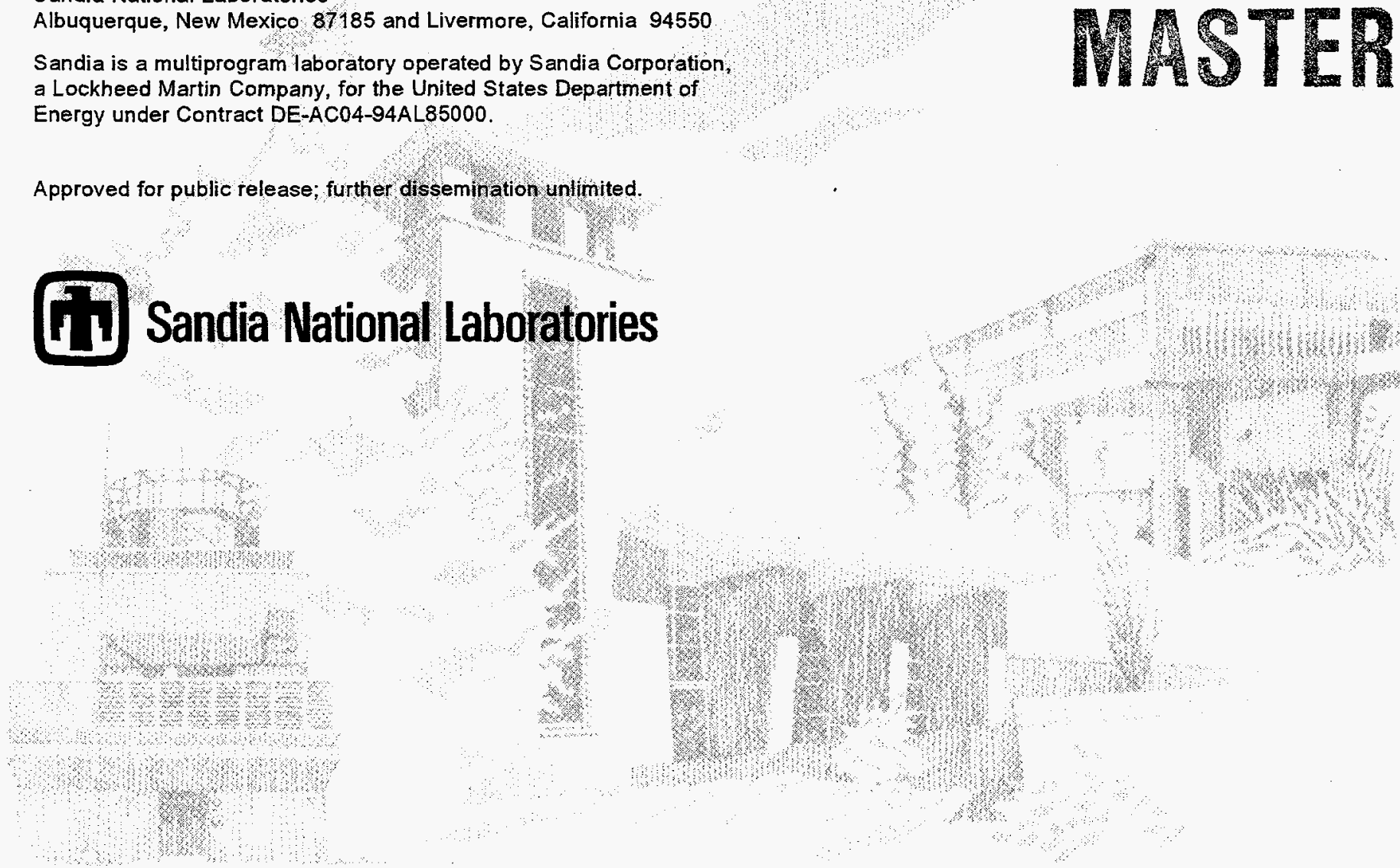
Issued by Sandia National Laboratories, operated for the United States Department of Eiergy by Sandia Corporation.

NOTICE: This report was prepared as an account of work sponsored by an agency of the United States. Government. Neither the United States Government nor any ąency thereof, nor any of their employees, nor any of their contractors, subcontractors, or their employees, makes any warranty, express or implied, or assumes any legal liability or responsibility for the accuracy, completeness, or usefulness of any information, apparatus, product, or process disclosed, or represents that its use would not infringe privately owned rights. Reference herein to any specific commercial product, process, or servise by trade name, trademark, manufacturer, or otherwise, does not necessarily constitute or imply its endorsement, recommendation, or favoring by the United States Government, any agency thereof, or any of their contractors; or subcontractors. The views and opinions expressed herein do not necessarily state or reflect those of the United States Government, any agency thereof, or any of their contractors.

Printed in the United States of America. This report has been reproduced directly from the best available copy.

Available to DOE and DOE contractors from

Office of Scientific and Technical Information

P.O. Box 62

Oak Ridge, TIJ 37831

Prices available from (615) 576-8401, FTS 626-8401

Available to the public from

National Technical Information Service

U.S. Department of Commerce

5285 Port Royal Rd

Springfield, V.4 22161

NTIS price codes

Printed copy: A03

Microfiche copy: A01 


\section{DESCAMIXR}

Portions of this doement may be illeaible in electonic image produets. Images are produced from the best available original docomentert 
SAND97-2899

Distribution

Unlimited Release

Printed November 1997

Category UC-704

\title{
Aspects of Two Corrosion Processes Relevant to Military Hardware
}

\author{
J. W. Braithwaite and R. G. Buchheit \\ Materials Aging and Reliability: Interfaces Department \\ Sandia National Laboratories \\ P.O. Box 5800 \\ Albuquerque, NM 87185-0340
}

\begin{abstract}
Corrosion is a leading material degradation mode observed in many military systems. This report contains a description of a small project that was performed to allow some of the important electrochemical aspects of two distinct and potentially relevant degradation modes to be better understood: environmentally assisted cracking (EAC) of aluminum alloys and corrosion in moist salt. Two specific and respective tasks were completed: (A) the characterization of the effect of aluminum microstructural variability on its susceptibility to EAC, and (B) the development of experimental and analytical techniques that can be used to identify the factors and processes that influence the corrosivity of moist salt mixtures. The resultant information constitutes part of the basis needed to ultimately predict component reliability and/or possibly to identify techniques that could be used to control corrosion in critical components. In Task A, a physical model and related understanding for the relevant degradation processes were formulated. The primary result from Task B included the identification and qualitative validation of a methodology for determining the corrosivity of salt mixtures. A detailed compilation of the results obtained from each of these two diverse tasks is presented separately in the body of this report.
\end{abstract}




\section{Task A: \\ An Assessment of the Susceptibility of High Strength Aluminum Alloys to Environmentally Assisted Cracking in Mixed Salt Solutions}

\section{Introduction (Task A)}

\section{Problem/Issue:}

Corrosion has been identified as an important concern with a number of aging military systems in which aluminum alloys are used as structural materials. Many engineering alloys (including aluminum and stainless steels) are susceptible to environmentally assisted cracking (EAC). EAC refers to the brittle failure of metal alloys under synergistic conditions of a tensile stress and a corrosive environment, and includes such mechanisms as stress corrosion cracking (SCC) and hydrogen embrittlement. Although EAC of these alloys represents a significant degradation problem in many applications, the relevant mechanisms are poorly understood. Therefore, remediation is largely empirical and reliability of existing and susceptible structures is difficult to assess.

Sandia has significant expertise relative to the important aspects for aluminum: EAC in other metal alloys, electrochemistry, and aluminum corrosion and metallurgy. In this task, these capabilities were applied to studying the different electrochemical responses of each of the various microstructural elements contained within a particular aluminum alloy. Recent work has shown the that microstructural variations can have a significant effect on SCC of stainless steel and a similar negative impact on a number of aluminum alloys has been proposed.

\section{Task Objective and Approach:}

The goal of this task was to provide a basis for the development of comprehensive analytical tools that can be used to predict component reliability and/or to possibly identify metallurgical changes (chemical or processing) to eliminate EAC from new structures. To accomplish this goal, the role microstructural and environmental interactions have on EAC of engineering aluminum alloys was characterized. Work focused on advancing two particular technical aspects:

1. identification of the key interactions, and

2. determination of microstructurally based anodic dissolution mechanisms.

Because of the limited scope of this task, activity was restricted to studying a specific aluminum alloy, $\mathrm{Al}$ 2024. The metallurgical characteristics of this material are described in the next paragraph. Standard DC electrochemical techniques (i.e. potentiodynamic/static polarization) were used as the principal experimental control and analysis methodologies. That is, the behavior of the key microstructural elements involved in the cracking process was identified and controlled using electrochemistry. 
$\mathrm{Al}-\mathrm{Cu}-\mathrm{Mg}-\mathrm{X}$ alloys are an important class of high strength, high toughness $\mathrm{Al}$ alloys that are used widely in aerospace applications. $\mathrm{Al}$ alloy $2024(\mathrm{Al}-4.4 \mathrm{Cu}-1.5 \mathrm{Mg}-0.6 \mathrm{Mn})$ is typical of this class. An optical micrograph of sectioned and polished Al 2024-T3 is shown in Figure 1. These alloys are microstructurally heterogeneous and contain a variety of second-phase particles. The $\mathrm{S}$ phase, $\mathrm{Al}_{2} \mathrm{CuMg}$, is significant because of its effect on mechanical properties and corrosion resistance. It is present (a) as large particles produced during solidification (Figure 2) and (b) as strengthening precipitates that are formed by a solution heat treatment/quenching process that is followed by natural or artificial aging. During aging, S-phase precipitation occurs in the $\alpha-\mathrm{Al}$ matrix and at grain boundaries. Grain boundary S-phase precipitation can occur with the formation of a Cu-depleted region at grain margins [1]. This phenomenon is known to increase susceptibility to stress corrosion cracking. The relative degree of grain boundary versus graininterior precipitation depends on the time and temperature of the aging treatment. Also, cooling at too slow a rate following solution heat treatment also permits grain boundary and grain interior S-phase precipitation to occur [1,2]. SCC susceptibility increases dramatically when the alloy is cooled slower than $550^{\circ} \mathrm{C} / \mathrm{s}$ through the $400^{\circ}$ to $315^{\circ} \mathrm{C}$ temperature range after solution heat treatment [1].

\section{Experimental Procedures (Task A)}

\section{Materials:}

The $\mathrm{Al} 2024$ samples used in this study were prepared from 1.5 inch thick $\mathrm{Al} 2024-\mathrm{T} 3$ plate stock. The nominal composition for Al 2024 is $\mathrm{Al}-4.4 \mathrm{Cu}-1.5 \mathrm{Mg}-0.6 \mathrm{Mn}$. Small amounts of $\mathrm{Ti}, \mathrm{V}$, and $\mathrm{Cr}$ are added as dispersoid formers to aid in thermomechanical processing. Tensile test samples were machined out of the plate in the long-transverse and short-transverse orientations.

In the mechanical and SCC tests, $\mathrm{Al} 2024$ was used in two different heat treatment conditions. In the first treatment (hereafter referred to as treatment 1), samples were solution heat treated at $495^{\circ} \mathrm{C}$ for 30 minutes. Samples were removed and immediately quenched in $20^{\circ} \mathrm{C}$ water. Samples were not artificially aged. However more than 30 days did elapse between heat treatment and testing during which natural aging and stabilization occurred. This first treatment ensured the materials would be in a condition consistent with the commercial T3 temper. Typically, this material is not susceptible to $\mathrm{SCC}$.

In the second treatment (treatment 2), samples were solution heat treated as before, but then were removed into air for 20 seconds and then quenched in $65^{\circ} \mathrm{C}$ water. Each sample was then artificially aged at $195^{\circ} \mathrm{C}$ for 8 hours. This treatment did not produce samples conforming to a commercial temper. Grain/subgrain boundary S-phase precipitation and $\mathrm{Cu}$-depleted zone formation were induced and, thus, electrochemically active pathways for localized attack were created.

High purity $\mathrm{Al}$ (99.999\%) and bulk synthesized $\mathrm{Al}_{2} \mathrm{CuMg}$ were used in electrochemical characterization experiments. Large crystals of the intermetallic $\mathrm{Al}_{2} \mathrm{CuMg}$ compound were synthesized by melting $\mathrm{Al}, \mathrm{Cu}$ and $\mathrm{Mg}$ and isothermally treating the melt in a two phase 
$\mathrm{Al}_{2} \mathrm{CuMg}$ (solid) and $\alpha-\mathrm{Al}$ (liquid) region of the ternary phase diagram. This procedure produced millimeter sized crystals suitable for electrochemical evaluation.

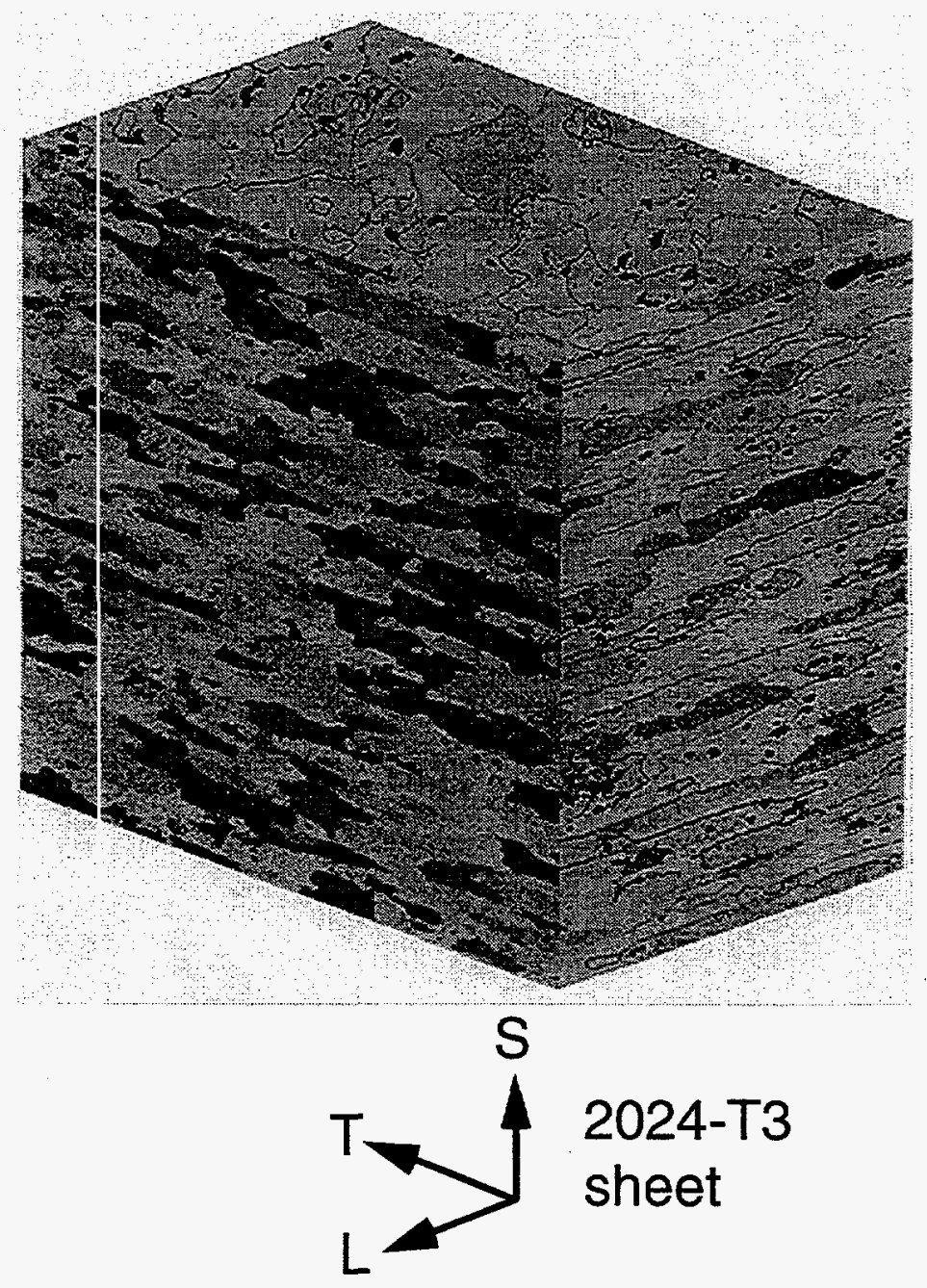

Figure 1. Optical micrograph composite of polished and etched orthogonal cross sections for rolled $\mathrm{Al}$ 2024-T3 sheet. $\mathrm{L}$, T, and S vectors denote the longitudinal, transverse and short directions respectively. The $L$ and $T$ directions define the rolling plane. Scale: $75 \mu \mathrm{m}=$

\section{Mechanical testing:}

Tensile testing was condıcted on a servo-hydraulic mechanical test system. The test samples were smooth-shouldered round bars $3.2 \mathrm{~mm}$ in diameter with a gage length of $25.4 \mathrm{~mm}$. The ends of the bars were threaded to fit into test grips and to prevent slippage. Tests were conducted at strain rates of $6 \times 10^{-4} / \mathrm{s}$ and samples were pulled to failure. Yield strength, ultimate tensile strength, strain to failure, and reduction in area data were collected on samples representing combinations of two different grain orientations and two different heat treatments. The two grain 
orientations refer how the samples were sectioned from a raw-stock plate. Both were taken transverse to the rolling direction: one aligned with the plate length (long transverse) and one aligned with the plate thickness (short transverse).

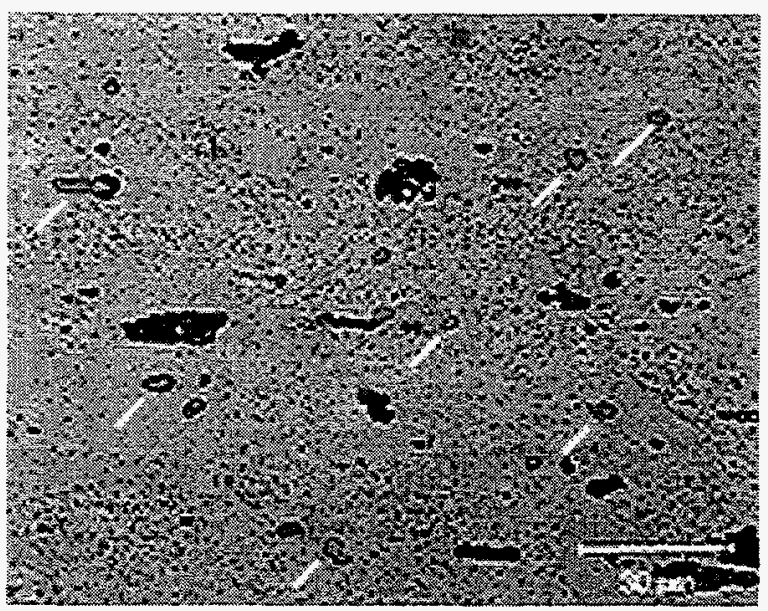

Figure 2. Optical micrograph indicating the location of S-phase particles that form in Al 2024 during solidification.

\section{Electrochemical testing:}

Anodic polarization experiments were conducted on materials selected to model discrete microstructural elements in the alloy. Tests were performed in a $0.1 \mathrm{M} \mathrm{NaCl}$ plus $0.1 \mathrm{M} \mathrm{Na} \mathrm{Cr}_{2} \mathrm{O}_{7}$ solution. Polarization scans were initiated $50 \mathrm{mV}$ negative to the open circuit potential for the electrode and scanned in the positive direction at $0.1 \mathrm{mV} / \mathrm{s}$ until the breakaway potential was detected.

Stress corrosion cracking testing:

Stress corrosion cracking tests were conducted under fixed displacement conditions using specially designed stressing jigs (Figure 3). Standard round tensile samples were loaded into the jigs and were outfitted with strain gauges to measure total strain. Samples were strained to a displacement corresponding to $75 \%$ of the yield strength measured in baseline tensile tests. The stressing jigs were masked off with a protective lacquer. Samples were then placed in the 0.1M $\mathrm{NaCl}$ plus $0.1 \mathrm{M} \mathrm{Na}_{2} \mathrm{Cr}_{2} \mathrm{O}_{7}$ test solution and potentiostatically polarized to a pre-selected value. Current versus time data was collected and samples were inspected periodically for evidence of failure. Tests were terminated either when samples mechanically failed by fracture or when 5 days of exposure time had elapsed. 


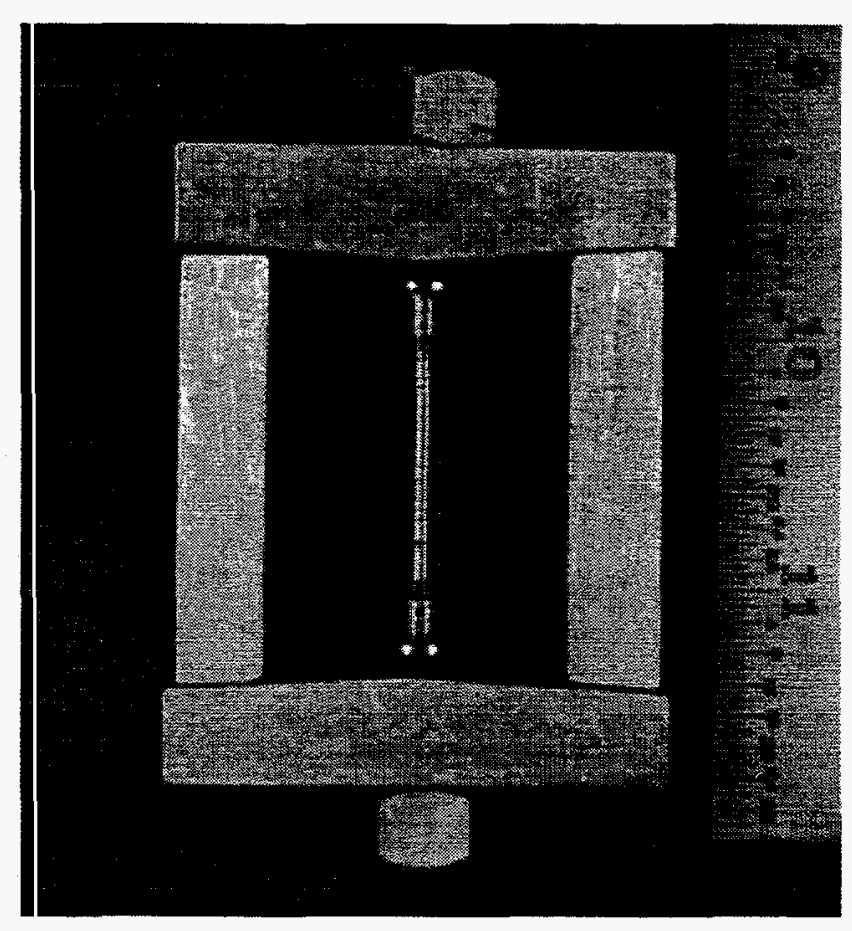

Figure 3. Photoyraph of the hardware and sample used to determine the susceptibility of $\mathrm{Al} 2024$ to stress corrosion cracking.

\section{Results and Discussion (Task A)}

\section{Microstructural characteristics:}

Figure 4 is a TEM micrograph showing the dispersion of second-phase particles found in Al 2024 after heat treatment 1 . There is a homogeneous distribution of dispersoids and small Sphase precipitates in the $\alpha$-Al grain interiors. There are several small S-phase precipitates that have formed on grain boundaries. Based on the processing of this sample, a Cu-depleted zone is not expected.

Figure 5 is a TEM micrograph showing the dispersion of precipitates after treatment 2 . In this case, slow cooling from solution heat treatment temperatures and the artificial aging treatment has induced formation of larger 0.5 to $1.0 \mu \mathrm{m}$ S-phase particles in the grain interiors and large precipitates on grain boundaries. Grain boundary precipitates of this large size are expected to form with an attendant $\mathrm{Cld}$-depleted zone. As noted in the previous section, this type of microstructure is expected to be more SCC susceptible.

\section{Baseline mechanical properties:}

Data from baseline mechanical testing of samples from both heat treatments and both orientations are shown in Table 1. There is little difference between the baseline tensile properties for both heat treatments. Given the inherent variability in properties that is normally 
obtained when samples such as these are machined from thick plate stock, the data for the longtransverse (L-T) orientation are generally comparable to handbook values reported for $\mathrm{Al} 2024$. That is, except for the yield-strength values that are about $20 \%$ lower, these L-T data are in the range of values reported for T3 and T4 commercial tempers [1]. The T3 temper is applicable to an alloy that was solution heat treated, cold worked, and naturally aged to a substantially stable condition. The $\mathrm{T} 4$ temper also produces a substantially stable condition but only requires a solution heat treatment and natural aging [1]. Alloy 2024 is commonly used in aerospace applications in the $\mathrm{T} 3$ and $\mathrm{T} 4$ tempers. It should be noted that $\mathrm{Al} 2024$ is also used in overaged tempers like T8X that are artificially aged past peak strength to improve SCC resistance. Al 2024 is one of the toughest alloys in commercial use as evidenced by the comparatively large total strain to failures and large reduction in area. Because of these properties, it is used in situations where strength and damage tolerance are important.

\section{Electrochemical behavior:}

Figure 6 shows anodic polarization curves collected in $0.1 \mathrm{M} \mathrm{NaCl}$ plus $0.1 \mathrm{M} \mathrm{Na}_{2} \mathrm{Cr}_{2} \mathrm{O}_{7}$ open to laboratory air for the materials used to model the microstructural elements considered in this study. In this environment, the breakaway (pitting) potentials for these materials are separated by tens to hundreds of millivolts. Replicate anodic polarization curves were collected and averaged values for the open circuit potential $\mathrm{E}_{\mathrm{oc}}$, the breakaway potential $\mathrm{E}_{\mathrm{br}}$, and the passive current density, $\mathrm{i}_{\text {pass }}$ are given in Table 2 . Averages were determined from a minimum of three replicate experiments. Reproducibility is very good and therefore the uncertainties associated with the average values are quite small. On the basis of these results, four regions of interest can be defined in terms of potential applied (refer to Figure 6):

a. in region "a", all microstructural elements considered are polarized negative to their respective breakaway potentials. All phases will corrode at their low passive rates, and localized corrosion susceptibility will be at a minimum. There is some as-yet undefined lower potential bound on this region beyond which localized corrosion susceptibility will increase. At large cathodic overpotentials, reduction reactions occurring on the alloy surface will generate a layer of alkaline solution. The protective passive film will breakdown and localized corrosion will occur. This phenomenon is generally referred to as cathodic corrosion.

b. in region "b", the alloy is polarized positive to the breakaway potential of the $S$ phase $\left(\mathrm{Al}_{2} \mathrm{CuMg}\right)$, but negative to the breakaway potentials of the $\alpha-\mathrm{Al}$ matrix phase and any $\mathrm{Cu}$-depleted zone that may have formed. Under these conditions, selective dissolution of S-phase particles is expected to occur.

c. in region " $c$ ", the alloy is polarized positive of the breakaway potentials of the S phase and any $\mathrm{Cu}$-depleted zone that may have formed, but is negative of the matrix phase. Selective dissolution of S-phase particles and any $\mathrm{Cu}$-depleted zone is expected.

d. in region "d", the alloy is polarized positive to all breakaway potentials for microstructure elements considered in this study. Aggressive corrosion attack is expected. 


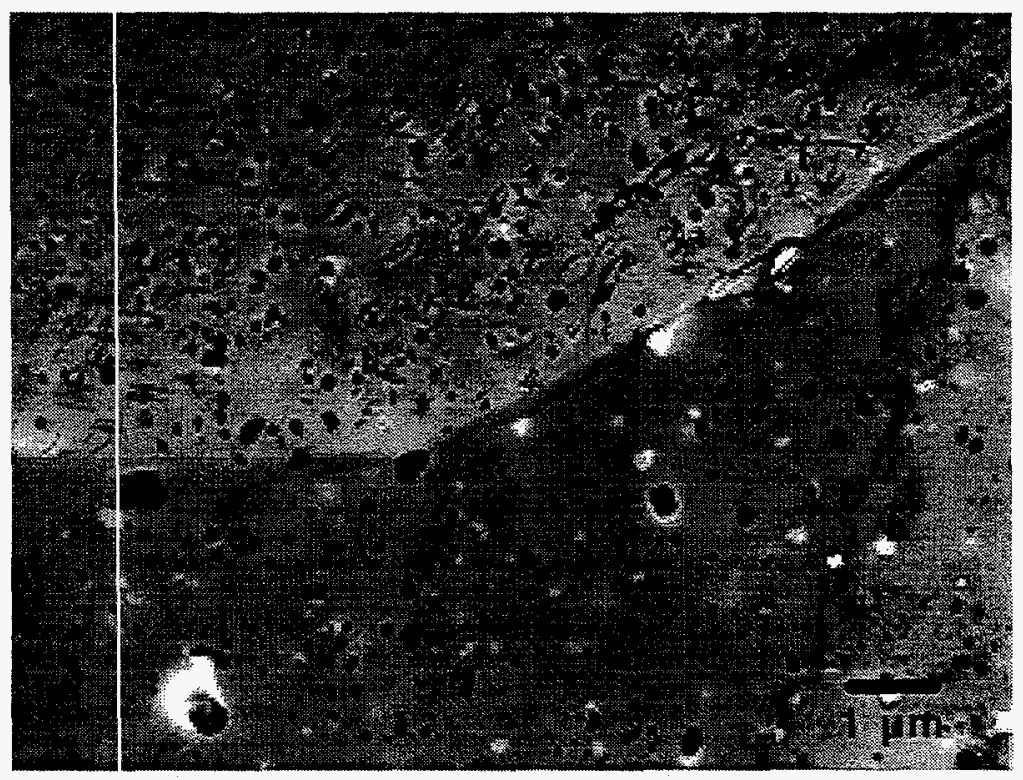

Figure 4. Brightfield TEM micrograph of Al 2024 subjected to treatment 1.

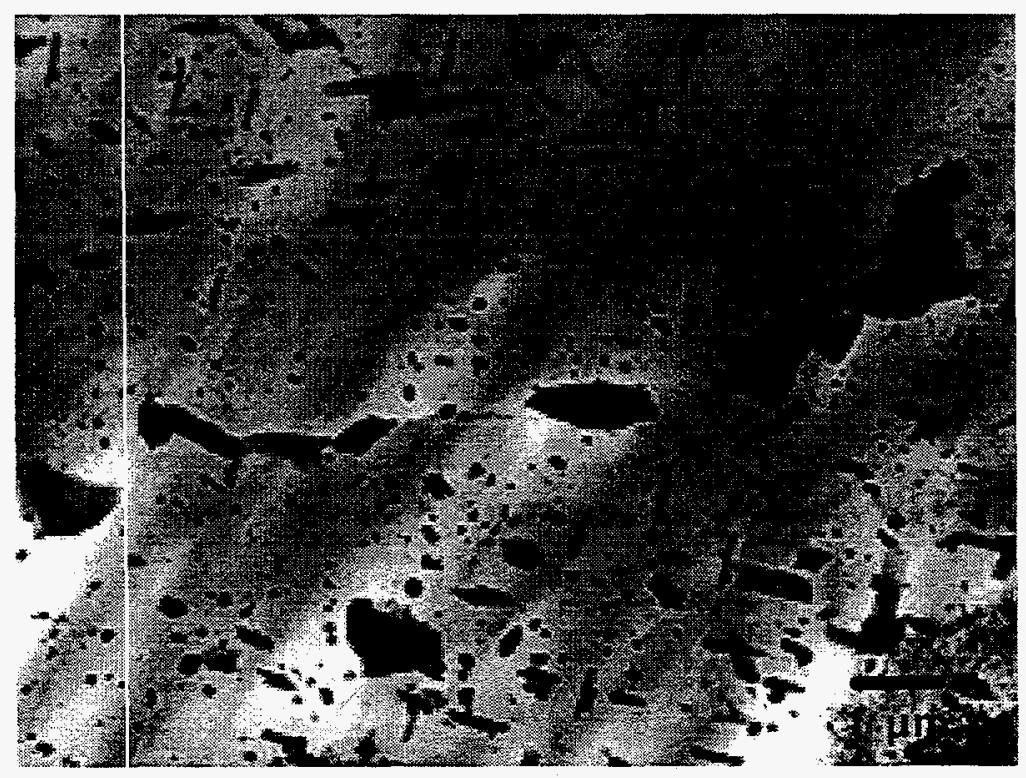

Figure 5. Bright field TEM micrograph of Al 2024 subjected to treatment 2. 
Table 1. Tensile test data for heat treated Al 2024 samples. Terminology: $\sigma_{\mathrm{ys}}$ - yield strength, UTS - ultimate tensile strength, $\varepsilon_{\mathrm{f}}$ - elongation, RA - reduction in area

\begin{tabular}{||ccccc||}
\hline \multicolumn{5}{|c||}{ Long-Transverse (measured) } \\
\hline $\begin{array}{c}\text { Sample } \\
\text { ID }\end{array}$ & $\begin{array}{c}\sigma_{\mathbf{y s}} \\
(\mathbf{k s i})\end{array}$ & $\begin{array}{c}\text { UTS } \\
(\mathbf{k s i})\end{array}$ & $\begin{array}{c}\boldsymbol{\varepsilon}_{\mathbf{f}} \\
(\boldsymbol{\%})\end{array}$ & $\begin{array}{c}\text { RA } \\
(\boldsymbol{\%})\end{array}$ \\
\hline T1-A & 41.7 & 67.2 & 18.9 & 20.0 \\
T1-B & 38.8 & 65.4 & 18.3 & 21.0 \\
T2-A & 38.4 & 63.8 & 20.0 & 17.0 \\
T2-B & 27.8 & 54.4 & 21.0 & 17.0 \\
\hline \multicolumn{5}{c}{ Long-Transverse (from reference [1]) } \\
\hline T3 & 50.0 & 70.1 & 18 & --- \\
T4 & 47.1 & 68.2 & 20 & -- \\
T8 & 65.3 & 70.0 & 6 & -- \\
\hline \multicolumn{5}{c}{ Short-Transverse (measured) } \\
\hline T1-A & 38.7 & 61.4 & 14.5 & 11.0 \\
T1-B & 38.8 & 61.9 & 14.9 & 11.0 \\
T2-A & 38.8 & 62.9 & 13.5 & 7.0 \\
T2-B & 29.1 & 53.7 & 13.2 & 9.0 \\
\hline \hline
\end{tabular}

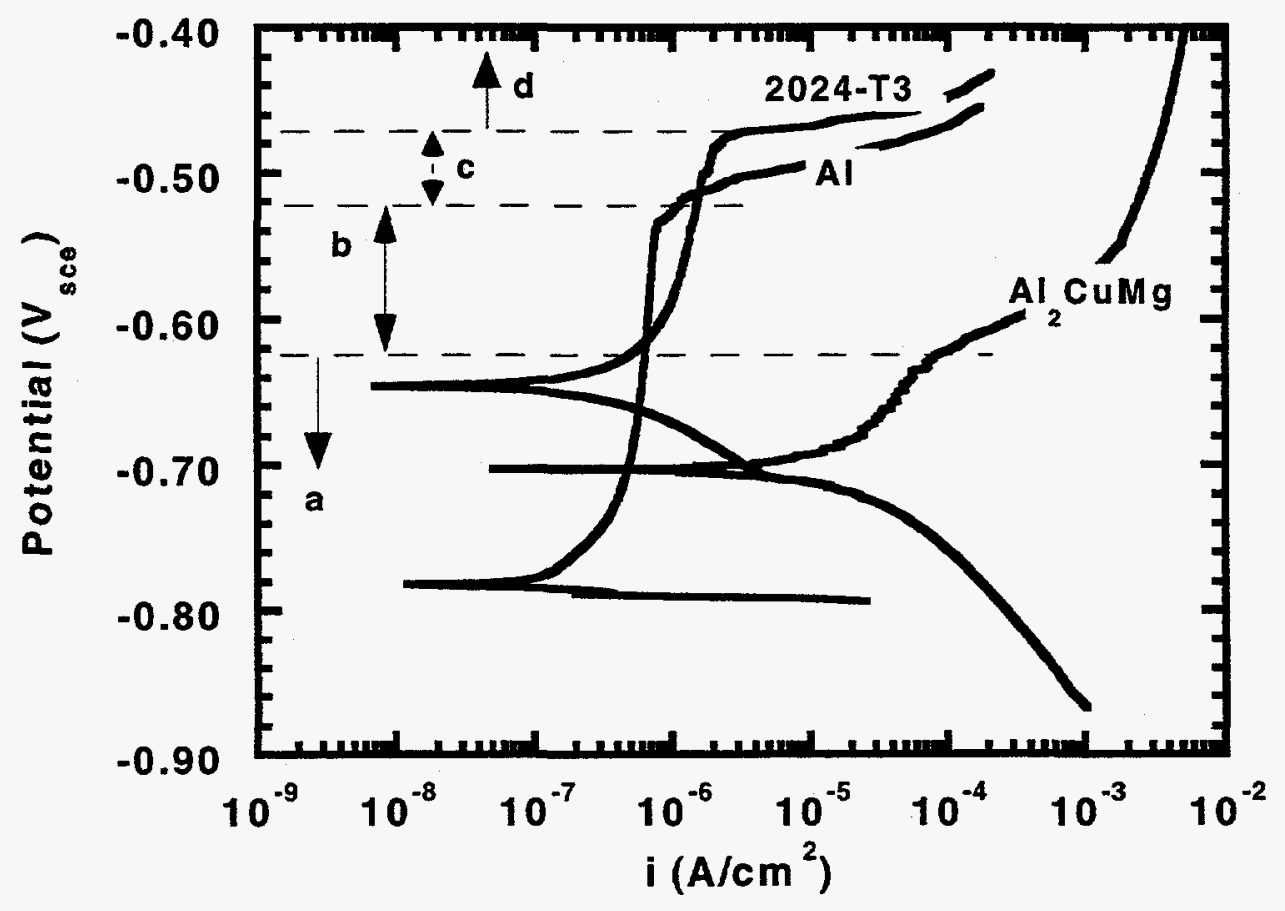

Figure 6. Anodic polarization curves collected on $0.1 \mathrm{M} \mathrm{NaCl}$ plus $0.1 \mathrm{M}$ $\mathrm{Na}_{2} \mathrm{Cr}_{2} \mathrm{O}_{7}$ for materials that simulate important microstructural elements in $\mathrm{Al}$ 2024. See text for explanation of potential windows a, b, c, and d. 
Table 2. Summary of anodic polarization data for materials tested in this study

\begin{tabular}{|cccc|}
\hline Material & $\mathbf{E}_{\text {oc }}$ & $\mathbf{E}_{\text {br }}$ & $\mathbf{i}_{\text {pass }}$ \\
$\left(\mathbf{V}_{\text {sce }}\right)$ & $\left(\mathbf{V}_{\text {sce }}\right)$ & $\left(\mu \mathbf{A m}^{2}\right)$ \\
\hline $\mathrm{Al} \mathrm{2024-T3}$ & $-0.646 \pm 0$ & $-0.476 \pm 0$ & $1.30 \pm 0.1$ \\
$99.999 \mathrm{Al}$ & $-0.782 \pm 0$ & $-0.515 \pm 0.01$ & $1.5 \pm 0$ \\
$\mathrm{Bulk} \mathrm{Al} \mathrm{Cl}_{2} \mathrm{CMg}$ & $-0.719 \pm 0.02$ & $-0.626 \pm 0.01$ & $86.0 \pm 75$ \\
\hline
\end{tabular}

\section{Stress corrosion cracking:}

In the SCC experiments, special attention was given to conditions involving applied potentials in regions $b$ and $c$. This situation was warranted because of the possibility that rapid cracking could occur due to localized attack at grain and subgrain boundaries populated with S-phase precipitates and associate: $\mathrm{Cu}$ depleted zones. In the first set of tests, the response of both L-T and S-T oriented samples; of each heat treatment was determined under potentiostatic polarization to $-0.570 \mathrm{~V}_{\text {sce }}$ (region " $\mathrm{b}$ "). Twelve tests were performed because each condition was replicated 3 times. At this potential, the samples were polarized to a value more positive than the breakaway potential of S-phase precipitates, but more negative than the breakaway potential for the matrix phase and the $\mathrm{Cu}$ depleted zone. Small currents (microampere) were measured indicating that very little electrochemical corrosion damage was occurring.

None of the region "b" samples fractured during the 5-day exposure period. The five day period was selected based on prior experience with $\mathrm{Al}$ alloy 2090 and on the desire to demonstrate mechanistic response ancl not necessarily susceptibility to long-term real-world conditions. Although the samples dicl not fail, it was possible that some localized corrosion or hydrogen uptake had occurred that could have a negative effect on mechanical properties. Therefore, at the end of the test, samples v/ere tensile tested and the resulting data are shown in Table 3. In comparison to the baselirie mechanical test data in Table 1, there is no strong indication that samples were embrittled or degraded in any way by this exposure. In addition, microscopic visual inspection was made of the sample periphery with no indication of intergranular corrosion or evidence of cracking.

A second set (6 total) of SCC samples (both L-T and S-T orientations) that were subjected to the more benign heat treatment 1 were immersed in the electrolyte and potentiostatically polarized to $-0.490 \mathrm{~V}_{\text {sce, }}$ a value that falls in region "c". At this potential, the samples were polarized to a value more positive than the breakaway potential for S-phase precipitates and the Cu-depleted zone, but more negative than the breakaway potential for the matrix phase. Large currents (milliampere) were measured indicating significant electrochemical corrosion damage occurred. All six of the samples, including those with the L-T orientation, fractured during the 5-day exposure period. However, it was not possible to determine exactly when final fracture took place because of the presence of significant corrosion products. A similar, although even faster, result would be expected for the material that was over-aged with heat treatment 2 . The presence 
of fracturing in the L-T samples is interesting because this orientation should be more resistant to $\mathrm{SCC}$ if the propagation followed the typical intergranular path.

Fracture surfaces were examined by scanning electron microscopy. Representative micrographs are shown in Figures 7 and 8, indicating that that severe intergranular and secondary cracking occurred. The embrittling effect of this treatment is judged to be severe because this degree of damage was induced in the samples considered to be more SCC resistant.

\section{Table 3. Tensile test data for heat treated Al 2024 samples polarized potentiostatically at $-\mathbf{0 . 5 7 0} \mathrm{V}_{\text {sce }}$ for 5 days while exposed to $0.1 \mathrm{M} \mathrm{NaCl}$ plus $0.1 \mathrm{M} \mathrm{Na}_{2} \mathrm{Cr}_{2} \mathrm{O}_{7}$. Terminology: $\sigma_{\mathrm{ys}}$ - yield strength, UTS - ultimate tensile strength, $\varepsilon_{\mathrm{f}}$ - elongation, $\mathrm{RA}$ - reduction in area}

\begin{tabular}{|c|c|c|c|c|}
\hline \multicolumn{5}{|c|}{ Long-Transverse } \\
\hline $\begin{array}{c}\text { Sample } \\
\text { ID }\end{array}$ & $\begin{array}{c}\sigma_{\mathrm{ys}} \\
(\mathbf{k s i})\end{array}$ & $\begin{array}{l}\text { UTS } \\
\text { (ksi) }\end{array}$ & $\begin{array}{c}\varepsilon_{f} \\
(\%)\end{array}$ & $\begin{array}{l}\mathbf{R A} \\
(\%)\end{array}$ \\
\hline $\mathrm{T} 1-\mathrm{A}$ & 41.9 & 65.2 & 22.0 & 21.0 \\
\hline T1-B & 42.6 & 66.0 & 20.4 & 14.0 \\
\hline $\mathrm{T} 1-\mathrm{C}$ & 41.3 & 64.5 & 20.8 & 20.0 \\
\hline $\mathrm{T} 2-\mathrm{A}$ & 39.5 & 62.4 & 18.7 & 10.0 \\
\hline $\mathrm{T} 2-\mathrm{B}$ & 34.8 & 53.6 & 18.0 & 12.0 \\
\hline $\mathrm{T} 2-\mathrm{C}$ & 41.1 & 63.5 & 22.0 & 18.0 \\
\hline \multicolumn{5}{|c|}{ Short-Transverse } \\
\hline $\mathrm{T} 1-\mathrm{A}$ & 34.4 & 63.4 & 14.1 & 7.1 \\
\hline T1-B & 41.6 & 60.2 & 11.0 & 4.0 \\
\hline $\mathrm{T} 1-\mathrm{C}$ & 40.2 & 61.6 & 16.4 & 9.0 \\
\hline $\mathrm{T} 2-\mathrm{A}$ & 36.1 & 54.0 & 9.4 & 5.0 \\
\hline T2-B & 31.9 & 53.3 & 13.6 & 6.4 \\
\hline $\mathrm{T} 2-\mathrm{C}$ & 31.6 & 51.0 & 9.4 & 5.0 \\
\hline
\end{tabular}

\section{Summary (Task A)}

This task involved studying the role microstructural and environmental interactions have on environmentally assisted cracking (EAC) of the engineering aluminum alloy Al 2024.

Electrochemical analysis was used in conjunction with static, fixed-displacement stress corrosion testing techniques. The cracking experiments focused on the electrochemical conditions (applied potentials) under which rapid cracking might be expected: (1) at a value more positive than the breakaway pitting potential of second-phase precipitate, but more negative than the breakaway potential for both the $\mathrm{Cu}$-depleted zone and the matrix phase, and (2) same as Set 1 except the potential was increased to a value more positive than the breakaway potential for the $\mathrm{Cu}$-depleted zone. No degradation (corrosion, cracking, decrease in properties) was produced in the Set 1 exposures, whereas relatively large amounts of electrochemical corrosion damage along with severe intergranular and secondary cracking occurred in the Set 2 samples. These results provide a correlation between the microstructural variations and their role in the susceptibility of $\mathrm{Al} 2024$ 
to EAC. That is, cracking is possible only in those environments were localized attack of particular second phase precipitates and an associated $\mathrm{Cu}$-depleted zone occurs at grain boundaries, but in which the matrix phase is unaffected.

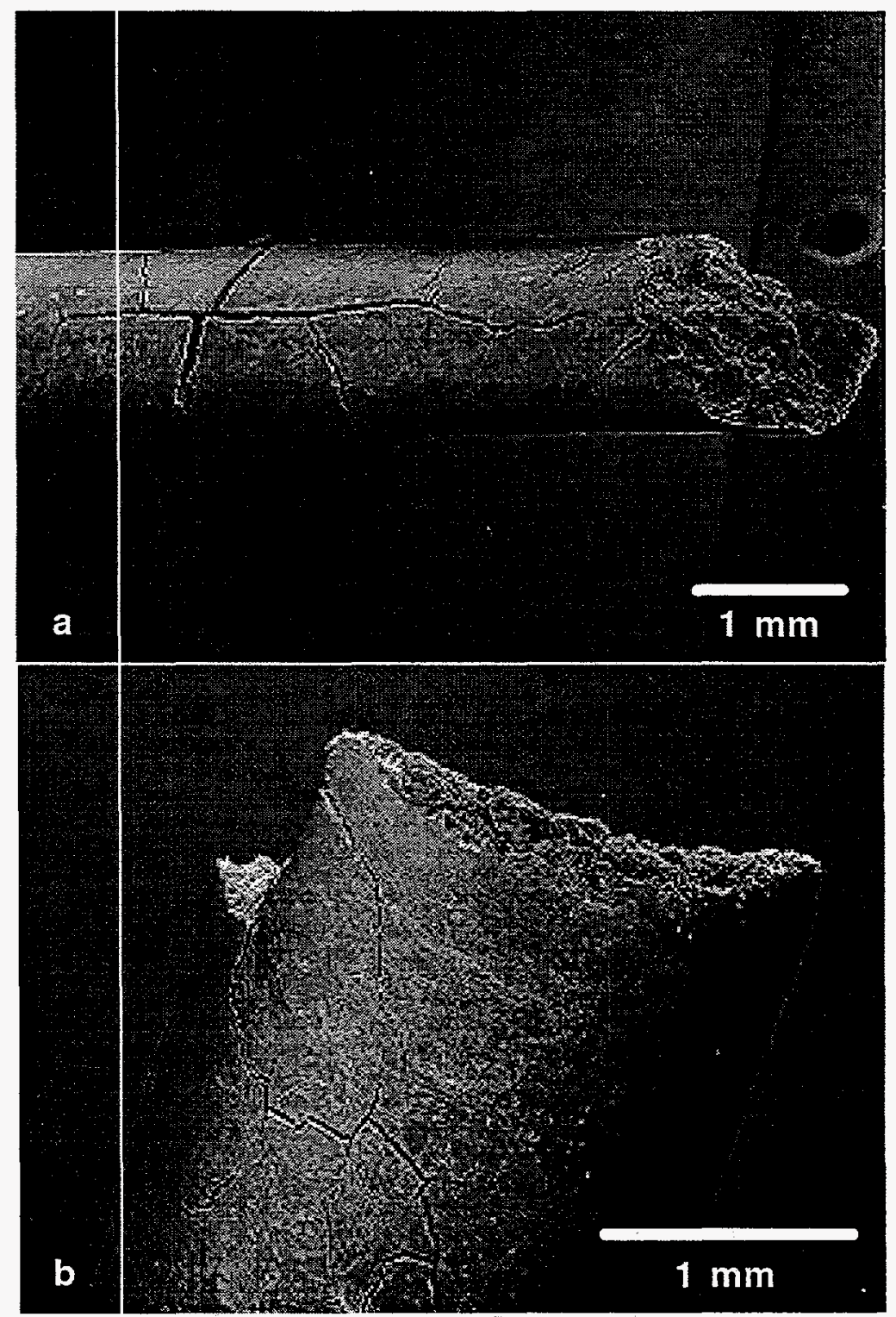

Figure 7. Scanning electron micrographs of Al 2024 subjected to heat treatrnent 1 after exposure to the electrolyte at $\mathbf{- 0 . 4 9 0} \mathrm{V}_{\text {sce }}$ for 5 days. Severe secondary cracking into aluminum matrix is shown $(L-T$ orientation). 


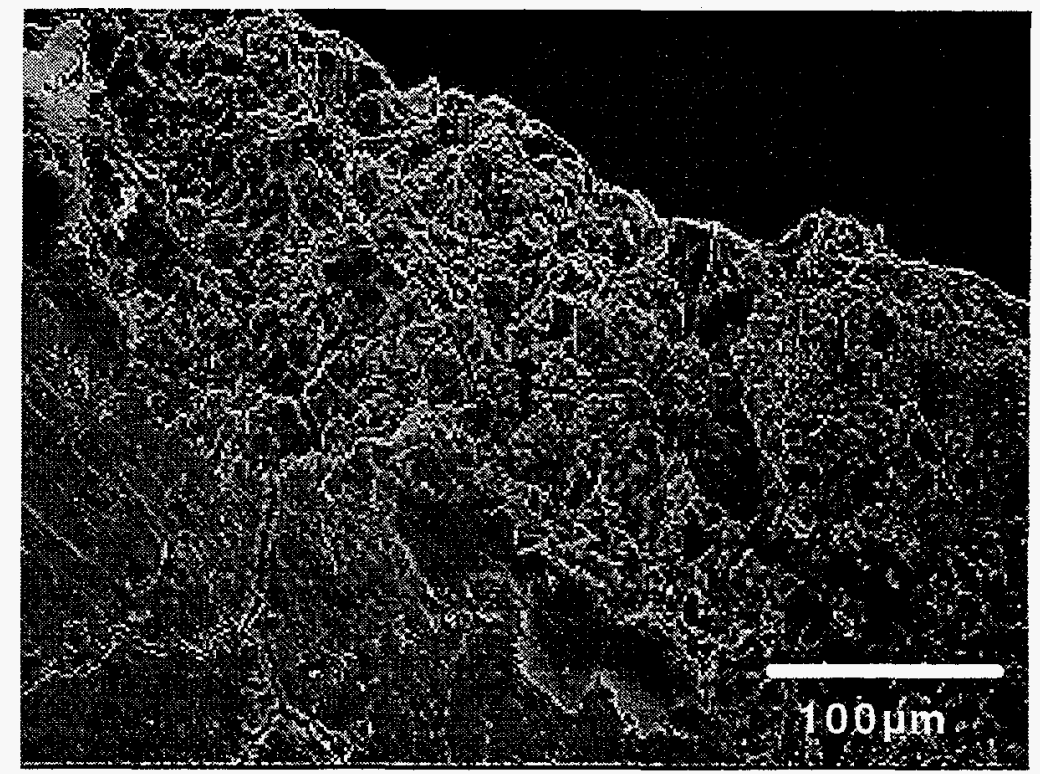

Figure 8. Scanning electron micrograph of the fracture surface of the sample shown in Figure 7. Intergranular fracture and secondary cracking are present.

\section{Task B: \\ Characterization of the Corrosivity of Moist Salt Mixtures}

\section{Introduction (Task B)}

\section{Problem/Objective:}

Salt mixtures of various formulations are used as active materials in a number of military components. Corrosion of adjacent metallic parts is of concern.. Usually, the common elements that must be present for observable corrosion to occur at ambient temperatures include an oxidant and some source of water. That is, ambient corrosion is typically electrochemical in nature, rather than direct dry metal. Both of these reactants can already exist in the system by unintentional contamination (of the salts themselves or finely divided metallic components), or be introduced into the system by other chemical degradation reactions or even by ingress from an external environment. Potentially, functional failure of the component can result. To date, the understanding of moist salt corrosion has been empirical at best.

Current corrosion engineering practice has not identified a procedure that can be used to easily determine the effect of environmental changes on the corrosivity of partially wetted metal surfaces, such as those obtained during exposure to moist salt. Related to this deficiency, the objective of this task was to develop techniques that can be used to identify what processes are 
actually influencing the degradation process and, as such, gain a better scientific understanding of the mechanisms by which corrosion occurs. This knowledge will enable effective decisions to be made relative to material processing or storage changes along with helping to assess long-term component reliability.

\section{Approach:}

The scope of this task was restricted to the study of a single set of salt components in varying ratios. Each of the selected components served one or more physical functions. This mixture is believed to be a reasonable model that will be applicable to other relevant combinations. In this regard, the following decisions were made:

- The salt mixture contained combinations of four essential elements: an oxidant, a hygroscopic agent, a corrosion accelerant, and a water-bearing mineral -

* potass um perchlorate $\left(\mathrm{KClO}_{4}\right)$ - baseline model salt component because it is used in many pyrotechnic devices and is believed to be an effective oxidant and hygroscopic agent.

* hydrated magnesium chloride $\left(\mathrm{MgCl}_{2} \cdot 6 \mathrm{H}_{2} \mathrm{O}\right)$ - known hygroscopic agent containing a corrosion accelerant $\left(\mathrm{Cl}^{-}\right)$.

* borax $\left(\mathrm{Na}_{2} \mathrm{~B}_{4} \mathrm{O}_{7} \cdot 10 \mathrm{H}_{2} \mathrm{O}\right)$ or gypsum $\left(\mathrm{CaSO}_{4} \cdot 2 \mathrm{H}_{2} \mathrm{O}\right)$ - water bearing minerals that easily dehydrate.

- Steel was selected as the baseline candidate metal: an easily corrodable and reproducible rnaterial like iron is required to identify any environmental and chemical effects and the: results are generally applicable to other materials, even active-passive metals such as stainless steel.

- Proven aqueous electrochemical techniques were used to identify the role of each chemical constituent.

- Long-term exposure of steel to various salt mixtures was performed to validate or confirm the electrochemical findings.

\section{Experimental Proceduris (Task B)}

Three types of characterization experiments were performed in this task: (1) salt hydration and dehydration behavior, (2) steel electrochemical polarization, and (3) static sealed corrosion kinetics. In all of the experiments, standard, as received, reagent grade chemicals were used. Each salt was crushed and sieved to -20 mesh. No humidity-based pretreatment was performed.

\section{Hydration/Dehydration}

The kinetics of hydration and dehydration along with the degree of reversibility of the various candidate salt materials and combinations were gravimetrically measured as a function of 
exposure time. In general, the selected salt was spread out in a petri dish and exposed as follows: (a) hydration in a constant-humidity chamber ( $85 \% \mathrm{RH})$ and (b) dehydration: either in an oven at $60^{\circ} \mathrm{C}$ for short time periods or in anhydrous $\mathrm{CaSO}_{4}$ desiccant for longer times ( $>1$ day).

\section{Electrochemical Polarization}

Standard DC polarization studies were performed on polished steel samples (see next paragraph) in a variety of aqueous solutions. The electrochemical instrumentation included an EG\&G PAR model 273 potentiostat in conjunction with Scribner Corrware software. A PAR flat-cell was used in which the exposed sample surface area is $1 \mathrm{~cm}^{2}$. When required, the solution was deaerated by purging with purified $\mathrm{Ar}$ for 1 hour prior to and then during the measurement. The solution was effectively saturated with each of the applicable components: $0.5 \%$ (wt.) $\mathrm{KClO}_{4}$, $1 \% \mathrm{MgCl}_{2} \cdot 6 \mathrm{H}_{2} \mathrm{O}, 2 \%$ borax, and fully saturated gypsum.

\section{Salt Corrosion}

Small steel samples $(1.2 \times 1.2 \times .25 \mathrm{~cm})$ were polished to $3 \mu \mathrm{m}$ alumina and placed in small sealed glass vials along with the selected host salt composition. A schematic diagram of the apparatus is shown in Figure 9. The matrix of experiments that was completed is defined in Table 4. The main experimental variables included salt composition, temperature, salt/metal ratio, metal configuration, and packing (indicated in Figure 9). Replicate samples were prepared (4 for each set) and removed at various times to obtain kinetic information. Corrosion was determined using visual examination and weight loss. Prior to final weighing, corrosion product was removed using a Pennwalt abrasive blaster with \#3 alumina particles.

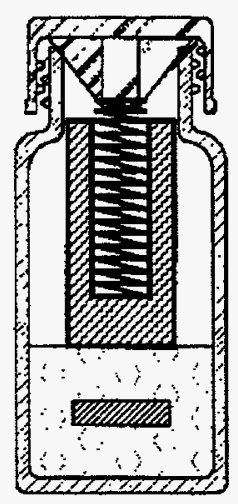

Figure 9. Schematic diagram of glass vial apparatus used to expose steel samples to moist salt. The outer glass container was $2.5 \mathrm{~cm}$ in diameter by $5.6 \mathrm{~cm}$ high. The spring and plastic packing assembly were used only for the exposures that tested packing density as a variable. 
Table 4. Listing of the configuration for moist salt exposure experiments. The salt composition refers to the weight percentage of $\mathrm{KClO}_{4} / \mathrm{gypsum} /$ $\mathrm{MgCl}_{2} \cdot 6 \mathrm{H}_{2} \mathrm{O}$. Each set contained 4 replicates and one parameter was varied from the baseline condition (set \#1 and 2).

\begin{tabular}{|c|c|c|c|c|c|c|c|}
\hline Expt Set \# & Description & Salt Comp & Salt Qnty & Temp & Metal & Packing & Atm \\
\hline 1 & baseline & $70 / 20 / 10$ & $10 \mathrm{gr}$ & 40 & coupon & no & air \\
\hline 2 & baseline rep & 1 & $"$ & " & 1 & 11 & $"$ \\
\hline 3 & higher T & $"$ & 1 & 65 & $"$ & $"$ & $\pi$ \\
\hline 4 & lower T & 4 & 11 & $a m b$ & $"$ & 11 & " \\
\hline 5 & low gypsum & $80 / 10 / 10$ & 11 & 40 & " & 11 & $\pi$ \\
\hline 6 & high $\mathrm{MgCl} 2$ & $60 / 20 / 20$ & $"$ & 1 & 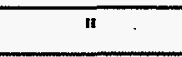 & 1 & $"$ \\
\hline 7 & packing & $70 / 20 / 10$ & $"$ & 1 & 4 & yes & $"$ \\
\hline 8 & no $\mathrm{O} 2$ & 11 & 1 & $"$ & $"$ & no & N2 \\
\hline 9 & salt/Fe ratio & 7 & 5 & $"$ & $"$ & $\pi$ & air \\
\hline 10 & wire & 11 & 10 & $"$ & $26 \mathrm{mil}$ & 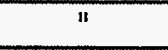 & $"$ \\
\hline 11 & alt salt 1 & $80 / 20 / 0$ & $\pi$ & 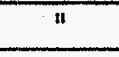 & coupon & $\pi$ & 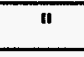 \\
\hline 12 & alt salt 2 & $80 / 0 / 20$ & $\pi$ & $"$ & $\frac{1}{11}$ & $"$ & $"$ \\
\hline 13 & $\mathrm{NiCr}$ & $\pi$ & 7 & $"$ & NiCr coup & $\pi$ & 4 \\
\hline
\end{tabular}

\section{Results (Task B)}

\section{Hydration/Dehydration}

Based on available literature information and the results of the characterization experiments performed in this study, the following significant statements can be made relative to each of the candidate salts:

\section{Single components}

1. Stored reagent grade borax is nearly completely hydrated and remains so even during periods of low ambient humidity. Borax will not uptake additional water beyond its nominal 10 waters of hydration.

2. Borax can be quickly and easily be dehydrated in an oven to levels below the pentahydrate, but the last few waters of hydration are very difficult to remove. Borax will dehydrate if left in a $\mathrm{CaSO}_{4}$-containing desiccator. However, the process is extremely slow, and how far the borax will dehydrate in this environment (i.e. the limit to the number of moles of water that can be lost) was not established during the 6 month timeframe of the test.

3. Rehydration of dehydrated borax in a humidity chamber only brings the level back up to the pentahydrate. It is unclear what conditions are necessary to fully rehydrate the compound.

4. $\mathrm{KClO}_{4}$ is not hygroscopic despite such statements in the literature and in MSDS information.

5. Crystalline $\mathrm{M}_{5} \mathrm{Cl}_{2} \cdot 6 \mathrm{H}_{2} \mathrm{O}$ uptakes water at a linear rate (over a period of up to a few days) to the point that a saturated clear liquid is formed. 


\section{$\underline{\text { Mixtures }}$}

1. Even without intimate contact, $\mathrm{MgCl}_{2} \cdot 6 \mathrm{H}_{2} \mathrm{O}$ can remove waters of hydration from borax. However, this process is slow at room temperature, resulting in only approximately $2 \mathrm{~mol}$ water lost/gained in 9 days.

2. The amount of water that a ternary borax $/ \mathrm{KClO}_{4} / \mathrm{MgCl}_{2} \cdot 6 \mathrm{H}_{2} \mathrm{O}$ mixture uptakes is directly related to the fraction of $\mathrm{MgCl}_{2} \cdot 6 \mathrm{H}_{2} \mathrm{O}$ present. If the fraction of $\mathrm{MgCl}_{2} \cdot 6 \mathrm{H}_{2} \mathrm{O}$ exceeds about $10 \%$, the entire mixture will liquefy.

These results indicate that in this system, borax can be a source of water, the $\mathrm{MgCl}_{2} \cdot 6 \mathrm{H}_{2} \mathrm{O}$ is a probable water sink and free chloride source, and any physical role of $\mathrm{KClO}_{4}$ is not obvious.

\section{Electrochemical Polarization}

The objectives of the aqueous DC polarization studies were to determine (1) the role of each electrolyte component in the corrosion process, and (2) if the DC polarization technique can be used to determine the corrosivity of salt mixtures. The specific questions related to \#1 that were answered included the following:

- does presence of chloride ion increase the corrosion rate?

- do passivating species exist?

- is oxygen required? (corollary - is $\mathrm{KClO}_{4}$ an effective oxidant?)

- is gypsum more effective than borax at promoting corrosion?

Although a wide range of polarization measurements were performed, the salient features are summarized in Figures 10-13. The region of interest to this work is the anodic behavior - that portion of the curve that is above the open circuit potential (indicated by the spike to very low current values). The measured current is proportional to the rate at which the steel is corroding.

The electrochemical data can also be used to determine the maximum corrosion rate under normal, non-polarized, conditions. Two methods are available: linear polarization and Tafel extrapolation. Both measure the rate of the electron charge transfer process and thus provide estimates of the maximum rate possible. That is, no restriction due to transport processes such as diffusion of oxidizing species is included. The calculated values for the conditions applicable to Figures 11 and 12 are compiled in Table 5. Based on this consistent set of polarization behavior and calculated corrosion rate, the conclusions stated in the following paragraphs can be drawn.

Chloride Ion: As shown in Figure 10, the presence of the chloride-containing $\mathrm{MgCl}_{2}$ has a substantial effect on the anodic behavior of steel. The limiting current is approaching an order of magnitude higher and the near open circuit slope (indicative of the corrosion rate) is much greater.

Passivation: Borax definitely passivates the steel surface (Figure 11). In all of the DC measurements made in which borax is present, a passive plateau is present in the anodic 
(corrosion) behavior just positive of the open circuit potential. Although, borax is commonly used as a pH buffer in fundamental steel corrosion studies, this effect was not appreciated prior to this study. This characteristic contrasts with the gypsum-containing solutions in which no passive behavior is present (also shown in Figure 11). Primarily because of the existence of this passive behavior, the calculated corrosion rates in all variants of the boraxcontaining solutions are significantly lower than in those containing gypsum (Table 5).

Role of Oxygen: In general, as oxygen is added to a solution in which steel is present, a positive shift in the ojen circuit potential and a corresponding increase in the corrosion rate is expected. However, in the moist salt mixtures considered in this study, the ability of the $\mathrm{KClO}_{4}$ to perform as an oxidant was unknown. For the environments in which borax is present, the deaerated polarization behavior with and without $\mathrm{KClO}_{4}$ is similar (Figure 12). It appears that $\mathrm{KClO}_{4}$ cannot effectively discharge on the electronically resistive passivation film formed on the steel surface in the presence of borax. With oxygen present, the opencircuit potential indeed does increase along with the corrosion rate (Table 5). One direct implication of this situation is that the transport of oxygen to the surface of the steel is probably a required process for corrosion to occur in borax-containing salt mixtures.

Polarization behavior in gypsum-containing solutions is quite different than that for borax (Figure 15). As noted above, there is no passive region and $\mathrm{KClO}_{4}$ does appears to be an active oxidant in that the open-circuit potential changes to more positive potentials. However, the calculated corrosion rates with and without $\mathrm{KClO}_{4}$ indeaerated solution are about the same. This discrepancy between qualitative observation and calculation demonstrates the difficulty with gaining quantitative information from DC polarization curves. Similar to the case of borax, the presence of oxygen definitely does increases the corrosivity (by an order of magnitude).

Borax vs. Gypsum: Because of the passivating nature of borax, corrosion in gypsum containing solutions is significantly greater. Of note, however, is that the absolute corrosion is still quite low. In general, corrosion-engineering practice states that a material is corrosion resistant if its uniform corrosion rate is $<50 \mu \mathrm{m} / \mathrm{yr}$. Thus, even in the worst case, steel would still be considered to be resistant to corrosion in any of these solutions, a conclusion that probably applies even to the majority of the moist-salt conditions described in the next section.

Applicability of DC Folarization: Based on the understanding gained in these studies and the correlation between these findings and the actual corrosion rates measured in moist salt mixtures (discussed in the next section), it appears that DC polarization can indeed be used as an effective tool in determining the factors affecting the corrosivity of moist salts. 


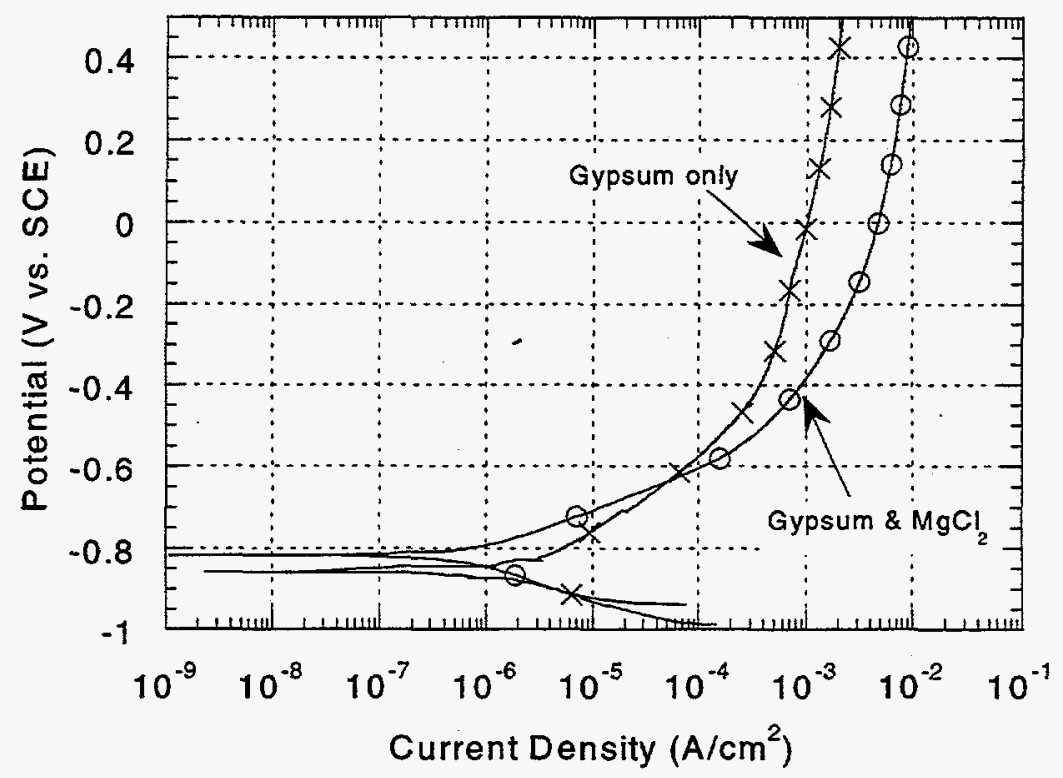

Figure 10. Chloride Effect: DC polarization behavior of steel in deaerated aqueous solution containing only gypsum (saturated) or gypsum (saturated) and $\mathrm{MgCl}_{2} \cdot 6 \mathrm{H}_{2} \mathrm{O}(\mathbf{1 \%})$.

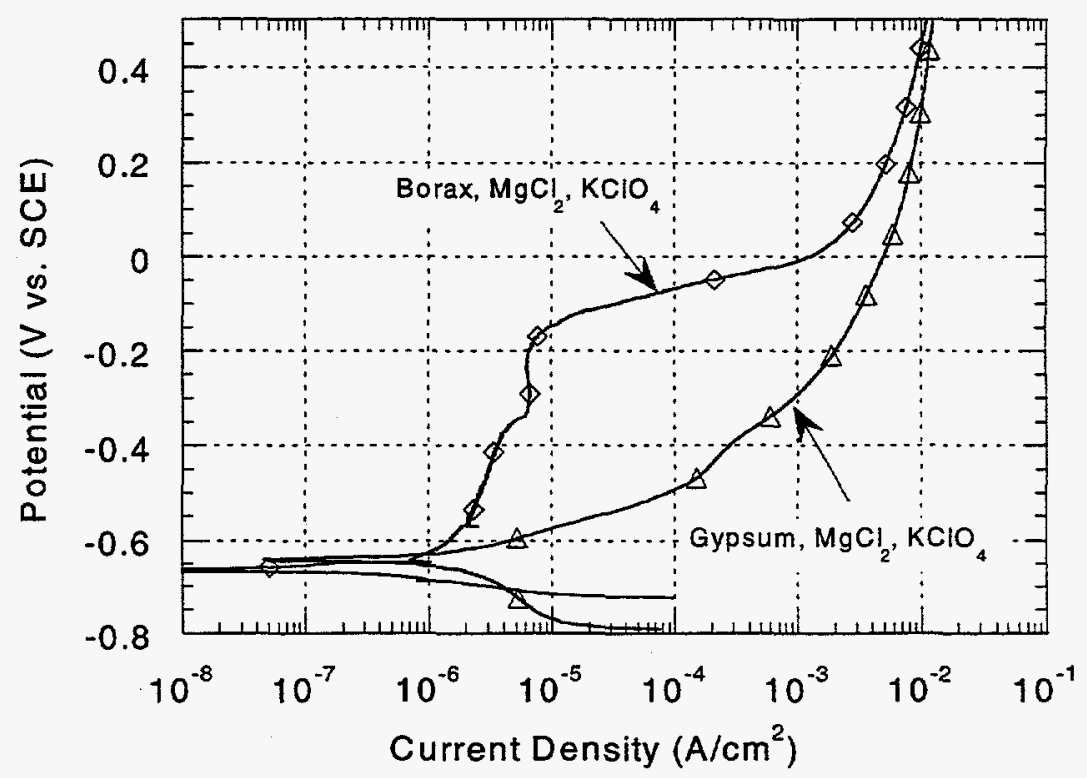

Figure 11. Gypsum vs. Borax: DC polarization behavior of steel in deaerated aqueous solution containing $\mathrm{KClO}_{4}(0.5 \%)$ and $\mathrm{MgCl}_{2} \cdot 6 \mathrm{H}_{2} \mathrm{O}(1$ wt. \%) with either gypsum (saturated) and borax (2\%). 


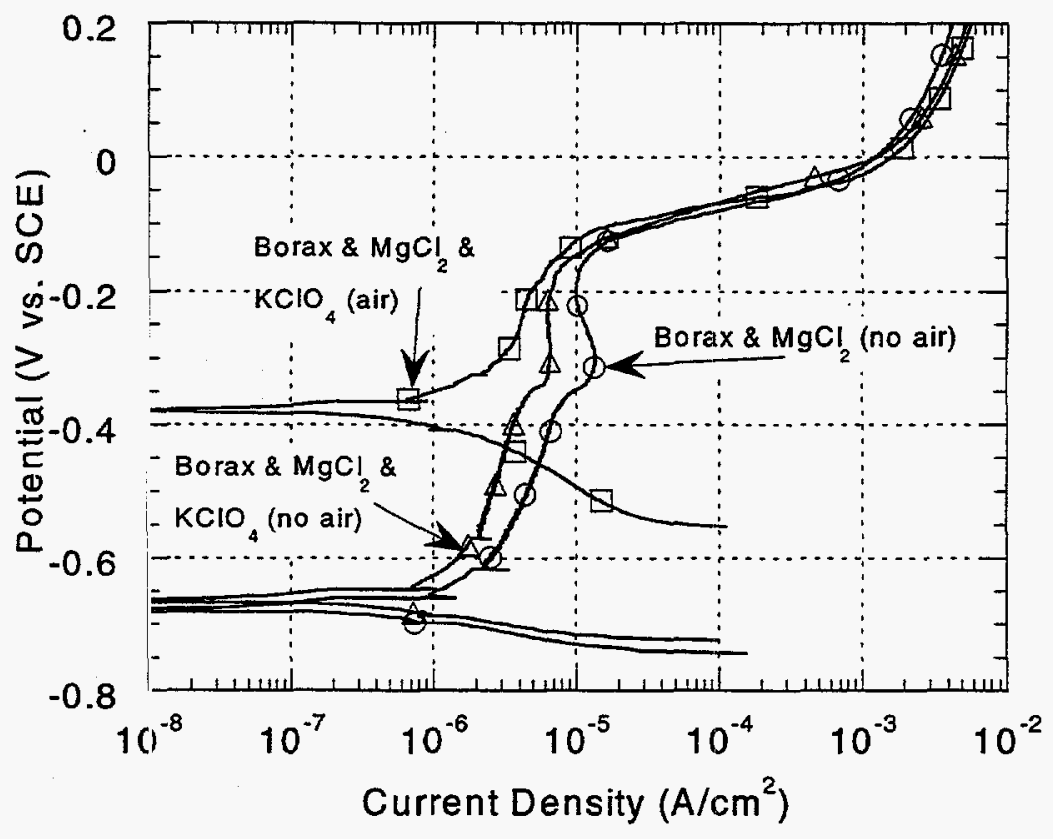

Figure 12. Oxidant Effect - Borax: DC polarization behavior of steel in aqueous solution containing various mixtures of borax $(2 \%), \mathrm{KClO}_{4}(0.5 \%)$, and/ol: $\mathrm{MgCl}_{2} \cdot \mathbf{6} \mathrm{H}_{2} \mathrm{O}(\mathbf{1 \%})$.

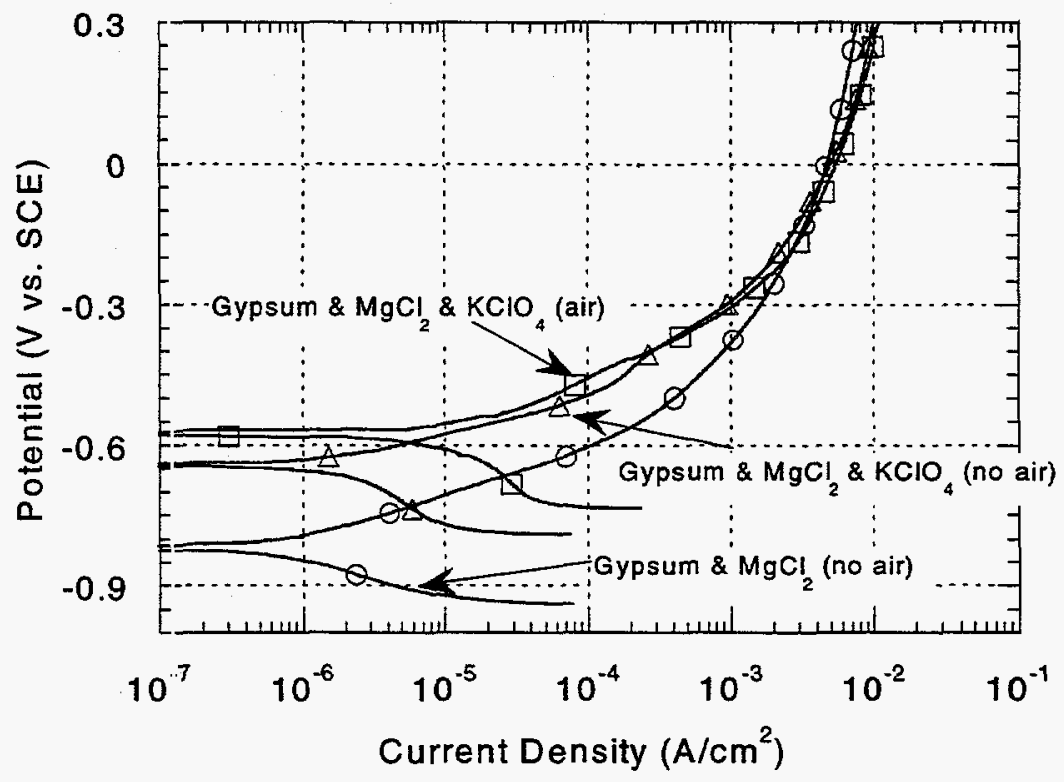

Figure 13. Oxidant Effect - Gypsum: DC polarization behavior of steel in aqueous solution containing various mixtures of gypsum (saturated), $\mathrm{KClO}_{4}$ $(0.5 \%)$, and/or $\mathrm{MgCl}_{2} \cdot 6 \mathrm{H}_{2} \mathrm{O}(1 \%)$. 
Table 5. Compilation of steel corrosion rates in aqueous solutions that were calculated from DC polarization measurements

\begin{tabular}{|c|ccc||}
\hline & \multicolumn{3}{|c||}{$\begin{array}{c}\text { Corrosion penetration rate } \\
(\mu \mathrm{m} / \mathbf{y r})\end{array}$} \\
\cline { 2 - 4 } $\begin{array}{c}\text { Constituents in } \\
\text { aqueous solution }\end{array}$ & $\begin{array}{c}\text { Linear } \\
\text { Method }\end{array}$ & $\begin{array}{c}\text { Tafel } \\
\text { Method }\end{array}$ & Ave. \\
\hline $\begin{array}{c}\text { Gypsum } \\
+\mathrm{MgCl}_{2} \& \text { deaerated }\end{array}$ & 3.8 & 2.7 & 3.2 \\
$+\mathrm{MgCl}_{2}, \mathrm{KClO}_{4} \&$ deaerated & 3.4 & 3.0 & 3.2 \\
$+\mathrm{MgCl}_{2}, \mathrm{KClO}_{4}$ \& aerated & 46 & 32 & 39 \\
Borax & & & \\
$+\mathrm{MgCl}_{2} \&$ deaerated & 0.22 & 0.14 & 0.18 \\
$+\mathrm{MgCl}_{2}, \mathrm{KClO}_{4} \&$ deaerated & 0.19 & 0.12 & 0.16 \\
$+\mathrm{MgCl}_{2}, \mathrm{KClO}_{4}$ \& aerated & 0.81 & 0.74 & 0.78 \\
\hline
\end{tabular}

\section{Salt Corrosion}

Limited studies completed prior to this project showed that corrosion in borax-containing salt mixtures was minimal and actually difficult to experimentally measure. As noted in the experimental section, this study focused on gypsum-containing salts. The majority of the kinetic results are shown in Figure 14. In these plots, the cumulative area-specific weight loss is plotted for each set of conditions as a function of time. This type of cumulative mass-loss plot provides a graphical representation of the progress of the corrosion reaction. For reference, a $10 \mathrm{mg} / \mathrm{cm}^{2}$ weight loss at 100 days corresponds to a corrosion rate of about $50 \mu \mathrm{m} / \mathrm{yr}$ (extrapolation of the elevated temperature Figure $14 \mathrm{~b}$ results). It should be noted again that each point on each curve was obtained using a separate sample. The qualitative conclusions that can be drawn include:

- The corrosion process is not as reproducible as desired. For examples, refer to the replicate baseline test information shown in Figure 14a, and the apparent reverse or negative tendencies for some selected points (Figure 14a and 14e). In Figures 14b-e, the replicate baseline data from Figure 14a were averaged. This lack of reproducibility is probably symptomatic of this system - the heterogeneous nature of the salt and how it packs onto the steel, the transport characteristics of oxygen through the salt, and the properties of the corrosion process/product layer itself.

- In general and as expected, the corrosion mechanism appeared to quite uniform in nature. That is, the coupons were penetrated on both sides and the edges in a uniform manner. In the worst case (higher temperature), some relatively broad pitting and edge attack occurred. 
- The specific environmental effects on the corrosion process were as expected based on existing knowledge and results from the characterization of salt hydration and polarization measurements:

* thermally activated (Figure 14a)

* independent of metal configuration (Figure 14b)

* insignificant impact of changes in ternary composition (Figure 14c)

* dramatic reduction in rate if one of the constituents (water bearing or hygroscopic/chloride containing) is removed (Figure 14d)

- The two unexpected occurrences are shown in Figure $14 \mathrm{e}$ and involve a reduced quantity of salt and the presence of mechanical packing. The expectation was that both of these situations would affect the transport of the important gaseous oxygen reactant. Therefore, with a reduced salt loading and shortened transport path, the rate should increase when it apparently decreased. On the other hand, packing had little effect (only one point was signficantly higher). Packing could decrease diffusivity but could also improve contact. As a final note and as expected, corrosion on the $\mathrm{NiCr}$ material was quite limited (Figure $14 \mathrm{e})$.

- Although qualitatively the corrosion observed in this set of moist salt exposures is in agreement with the aqueous polarization results, the absolute value of the rate is quite different. The single point of direct comparison is from the ambient temperature exposures where the calculated rate in the ternary aqueous environment is $10-20$ times greater than the $2-4 \mu \mathrm{m} / \mathrm{yr}$ applicable to the ternary moist salt (Figure $14 \mathrm{a}, 20^{\circ} \mathrm{C}$ data). Such a dramatic difference is expected because corrosion is an electrochemical process and the degree of wetting and ionic conductivity in the moist salt has to be significantly lower. As mentioned in the previous section, steel would be considered to be corrosion resistant under most of the low and medium temperature moist salt conditions because the corrosion rate is $<50 \mu \mathrm{m} / \mathrm{yr}$. At the high temperature studied $\left(65^{\circ} \mathrm{C}\right)$, however, corrosion is significant with the highest measured rate being about $650 \mu \mathrm{m} / \mathrm{yr}$ after 22 days.

One desired product of this task was a kinetic model of the process that permits prediction and better process understanding. Under neutral aqueous conditions, the corrosion rate of steel is usually controlled by the rate of oxygen supply to the surface. As such, two stages are often observed for samples with flat-plate geometries as used in the majority of this study: (I) initial linear region in which diffusion through a constant-thickness boundary layer controls and (II) a parabolic region that is caused by diffusion through an increasingly thick solid rust layer. In some cases, linear stage I behavior is produced by a charge-transfer controlled process. Unfortunately, the quality of the data collected in this study is not suitable (too inconsistent) for formulating such a model and an associated understanding of the physical processes. Considering plausible mechanisms and the need for statistical significance, it is not even possible to define a reasonable empirical model for the majority of the data. The one exception appears to be the initial corrosion rates as a function of temperature - that is, those to about 40 days where linear behavior is present. An Arrhenius plot using the derived rate data is shown in Figure 15. The associated 
apparent activation energy is $21 \mathrm{kcal} / \mathrm{mole}$, a value that is substantially higher that typically determined for steel in aqueous solutions (range of 3-5 kcal/mole). Obviously, the much higher activation energy supports the existence of a dramatically different corrosion mechanism.

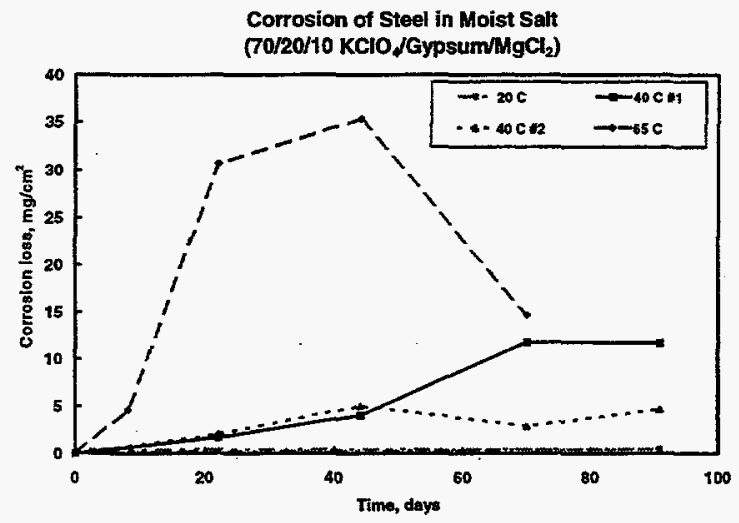

(a)

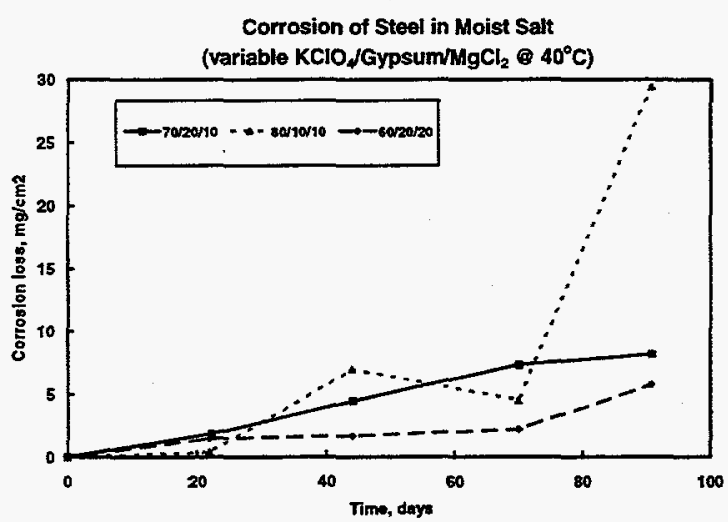

(c)

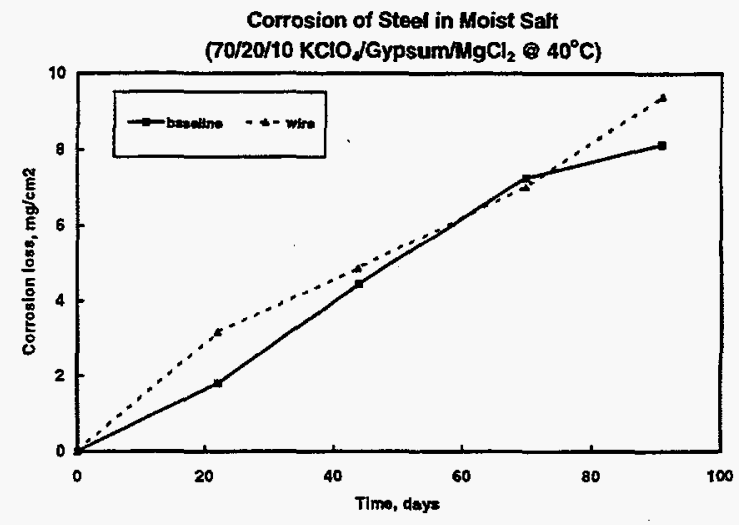

(b)

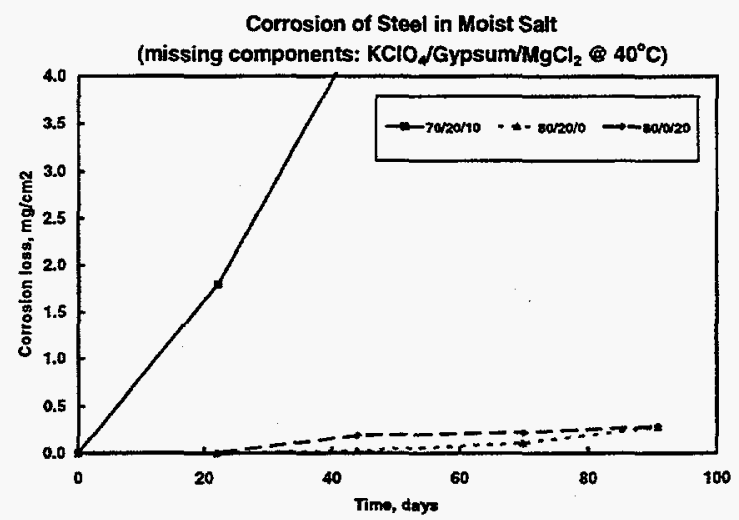

(d)

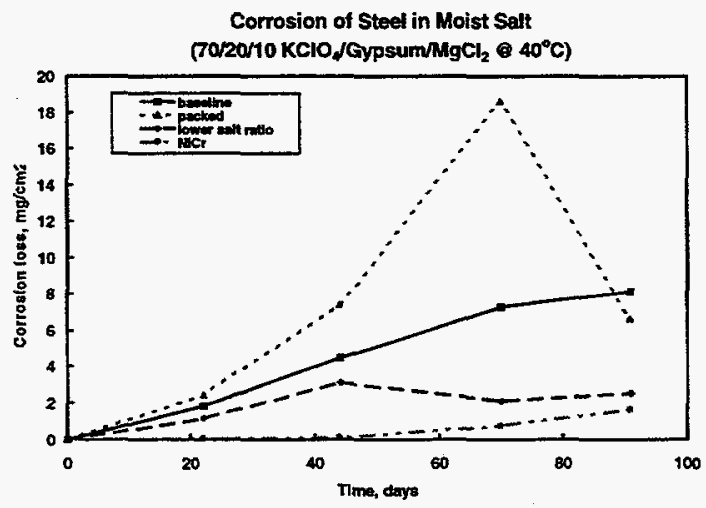

(e)

Figure 14. Effect of a number of environmental parameters on the corrosion kinetics of steel in moist salt mixtures - (a) temperature, (b) steel configuration (wire vs. flat coupon), (c) variable ternary composition, (d) missing ternary component, and (e) other (packed salt, $50 \%$ less salt, $\mathrm{NiCr}$ ). The "baseline" set in b-e represents the average of the two $40^{\circ} \mathrm{C}$ experiments presented in a. 


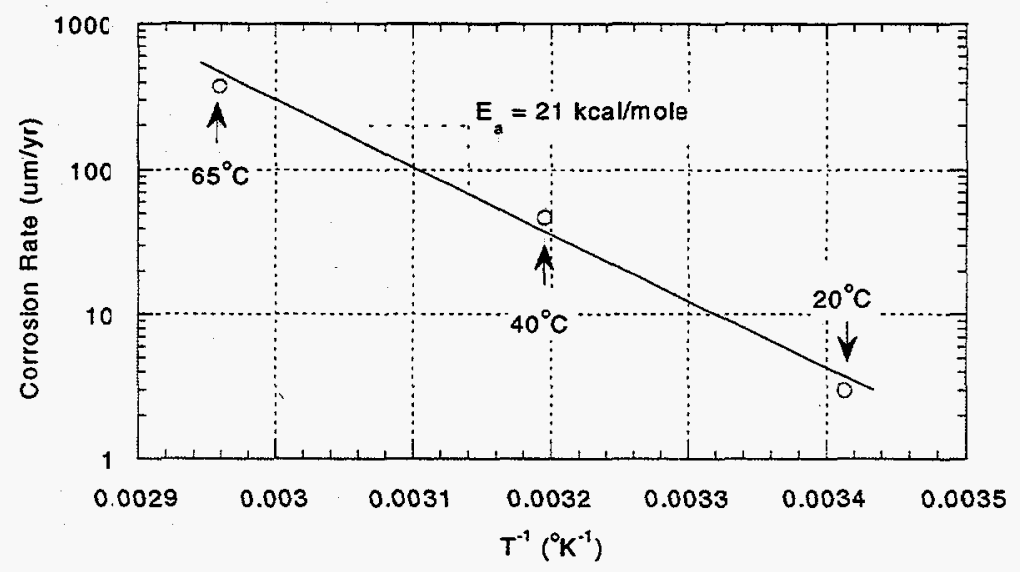

Figure 15. Arrhenius plot of the initial corrosion rate data (44 days) assuming linear kinetics.

\section{Summary (Task B)}

In this task, methodologies have been identified and qualitatively validated for determining the corrosivity of salt mixtures. Dry oxidation of most engineering metals at or near ambient temperatures is a very slow process. For the degradation rate to become appreciable, an aqueous or adsorbed water phase along with an effective oxidant are required. Their presence enables aqueous-like electrochemical processes to become functional. Then, depending on the extent of the moisture, its physical nature, and the existence of other contributors (such as agents that destroy passivating layersi), corrosion can proceed at measurable rates. Simple hydration/dehydration experiments can be used with candidate materials to determine how water present in the system will distribute. Aqueous DC polarization techniques appear to be an effective way to quickly identify the role of the non-aqueous constituents in the corrosion process (e.g., passivating agents, oxidants). However, the absolute rate of steel corrosion in the salt compositions studied is relatively low. As such, long-term exposure to actual conditions will be required to characterize and then validate the response. A positive feature in this regard is that the activation energy is much higher than occurs in aqueous systems. Thus temperature could be an effective age accelerant.

\section{References}

1. J. E. Hatch, ed., Aluminum: Properties and Physical Metallurgy, ASM, Metals Park, OH, 1986, p. 362

2. C. R. Brooks, Heat Treatment, Structure and Properties of Non-Ferrous Alloys, ASM, Metals Park, OH, 1982, p. 132 


\section{ACKNOWLEDGEMENT}

This work was supported by the United States Department of Energy under Contract DE-AC0494AL85000. Sandia is a multiprogram laboratory operated by Sandia Corporation, a Lockheed Martin Company, for the United States Department of Energy. The authors would like to especially thank Mike Martinez and Angie Butkovich for their significant efforts that involved the experimental portions of this project.

\section{DISTRIBUTION}

2 Dr. R. G. Buchheit

Department of Materials Science and Engineering

The Ohio State University

477 Watts Hall

2041 College Rd.

Columbus, $\mathrm{OH} 43210$

Sandia:

$5 \quad$ MS 0340

J. W. Braithwaite, 1832

$1 \quad$ MS 0340

W. R. Cieslak, 1832

$3 \quad$ MS 0877

M. J. Carr, 5903

$1 \quad$ MS 9018

Central Technical Files, 8940-2

$5 \quad$ MS 0899

Technical Library, 4916

$2 \quad$ MS 0619

Review and Approval Desk, 12690 for DOE/OSTI 